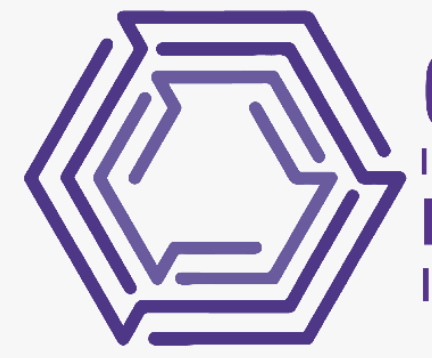

COINTER PDVGT 2020

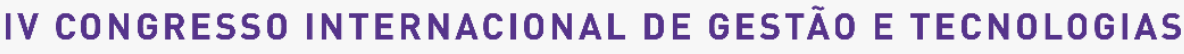
Edição $100 \%$ virtual | 02 a 05 de dezembro ISSN:2596-0857 | PREFIXO DOI:10.31692/2596-0857

\title{
DESENVOLVIMENTO DE APLICATIVO PARA SOCIALIZAÇÃO DE PROBLEMAS E POSSÍVEIS SOLUÇÕES EM GRUPOS DE TRABALHO.
}

\author{
DESARROLLO DE APLICACIONES PARA LA SOCIALIZACIÓN DE \\ PROBLEMAS Y POSIBLES SOLUCIONES EN GRUPOS DE TRABAJO.
}

\section{APPLICATION DEVELOPMENT FOR SOCIALIZATION OF PROBLEMS AND POSSIBLE SOLUTIONS IN WORK GROUPS.}

\author{
Apresentação: Comunicação Oral \\ Kleber Danylo Mendes da Silva ${ }^{1}$; Renata Cristine de Sá Pedrosa Dantas ${ }^{2}$
}

DOI: https://doi.org/10.31692/2596-0857.VCOINTERPDVGT.0114

\begin{abstract}
RESUMO
O presente trabalho aborda o desenvolvimento de um aplicativo para dispositivos móveis, que busca solucionar os problemas de comunicação em grupos de trabalho. Analisando que o alto fluxo de informação pode causar ruídos na comunicação e interações entre os indivíduos, logo o artigo aborda uma possível solução para essa questão. A abordagem presente trabalho discorre o processo para o entendimento da problemática além do desenvolvimento da solução; Utilizando as experiências de comunicação através dos meios digitais do grupo de estudos GEPARC - Grupo de Estudos e Pesquisas em Administração e Redes de Cooperação, que possui sua atuação em instituições de ensino e vem sendo acompanhado desde 2020 nesta pesquisa, através do Programa de Iniciação Científica no Instituto Federal de Pernambuco. Para buscar essa possível solução foi realizado um questionário no modelo qualitativo e quantitativo com 10 perguntas que buscou entender o motivo e as possíveis causas dos conflitos e ruídos na comunicação, focando no meio digital. Para dar base ao desenvolvimento dessa primeira versão do que seria o software chamado de RememberMe, que tem como objetivo organizar os grupos de trabalhos e criar lembretes de reunião ou qualquer outra atividade como preenchimento de questionário entre outros. Dessa forma a atividade fica fixada natela do usuário informando quanto tempo falta para determinada atividade acontecer, criando um funil de comunicação e passando para os membros da equipe apenas aquelas informações que são realmentenecessárias.
\end{abstract}

Palavras Chave: Desenvolvimento de aplicativo, comunicação, grupos de trabalho

\footnotetext{
1 Aluno do Curso Superior em Análise e Desenvolvimento de Sistemas, Instituto Federal de Pernambuco Campus Recife, kdms@discente.ifpe.edu.br

2 Doutora em Ciência da Computação pelo Centro de Informática/UFPE, Professora do Instituto Federal de Pernambuco - Campus Recife, renatadantas@recife.ifpe.edu.br
} 


\begin{abstract}
O
Este trabajo aborda el desarrollo de una aplicación para dispositivos móviles, que busca resolver problemas de comunicación en grupos de trabajo. Analizando que el alto flujo de información puede causar ruido en la comunicación y las interacciones entre individuos, el artículo aborda una posible solución a este problema. El enfoque de este trabajo analiza el proceso para comprender el problema más allá del desarrollo de la solución; Aprovechando las experiencias de comunicación a través de medios digitales del grupo de estudio GEPARC - Grupo de Estudios e Investigación en Redes de Administración y Cooperación, que trabaja en instituciones educativas y ha sido acompañado desde 2020 en esta investigación, a través del Programa de Iniciación Científica en el Instituto Federal de Pernambuco. Para buscar esta posible solución, se realizó un cuestionario en un modelo cualitativo y cuantitativo con 10 preguntas que buscaban comprender el motivo y las posibles causas de los conflictos y ruidos en la comunicación, centrándose en el medio digital. Apoyar el desarrollo de esta primera versión de lo que sería el software llamado RememberMe, que tiene como objetivo organizar grupos de trabajo y crear recordatorios de reuniones o cualquier otra actividad como la cumplimentación de un cuestionario, entre otras. De esta forma, la actividad se fija en la pantalla del usuario, informando cuánto tiempo queda para que se lleve a cabo una determinada actividad, creando un embudo de comunicación y pasando a los miembros del equipo solo aquella información que sea realmente necesaria.
\end{abstract}

Palabras clave: desarrollo de aplicaciones, comunicación, grupos de trabajo

\begin{abstract}
This work addresses the development of an application for mobile devices, which seeks to solve communication problems in work groups. Analyzing that the high flow of information can cause noise in communication and interactions between individuals, then the article addresses a possible solution to this issue. The approach in this work discusses the process for understanding the problem beyond the development of the solution; Using the experiences of communication through digital media of the GEPARC study group - Group of Studies and Research in Administration and Cooperation Networks, which works in educational institutions and has been accompanied since 2020 in this research, through the Scientific Initiation program at the Federal Institute of Pernambuco. To seek this possible solution, a questionnaire was carried out in the qualitative and quantitative model with 10 questions that sought to understand the reason and possible causes of conflicts and noise in communication, focusing on the digital medium. To support the development of this first version of what would be the software called RememberMe, which aims to organize work groups and create meeting reminders or any other activity such as filling out a questionnaire, among others. In this way, the activity is fixed on the user's screen, informing how much time is left for a given activity to take place, creating a communication funnel and passing on to the team members only those information that are really necessary.
\end{abstract}

Keywords: Application development, communication, workgroups 


\section{INTRODUÇÃO}

Segundo a LEI N 9394/96 que diz a respeito da matriz educacional no país, define no seu artigo 43 "VII - promover a extensão, aberta participação da população, visando a difusão das conquistas e benefícios resultantes dá criação cultural e da pesquisa científica e tecnológica geradas na instituição" (BRASIL, 1996). Compreendendo que o Ensino é o processo de construção do saber, com apropriação do conhecimento historicamente produzido pela humanidade, a pesquisa como o processo de materialização do saber a partir da produçãode novos conhecimentos baseado de problemas emergentes da pratica social e a Extensãopode ser entendido como processo educativo, cultural e científico, de intervenção nos processos sociais e identificação de problemas da sociedade, buscando a democratização dos conhecimentos acadêmicos. Na era digital, filtrar as altas quantidades de informações e estímulos visuais recebidos pelas redes sociais muitas vezes se torna um desafio. Segundo Oliveira e colaboradores (2001), os Softwares aplicativos entram na categoria de aplicativos que não foram desenvolvidos com fins educacional, mas podem ser utilizados para essa finalidade.

No Instituto Federal de Pernambuco (IFPE) existem alguns grupos de trabalho que estão cada vez mais tentando aprimorar os seus processos de comunicação e troca de informações. Neste sentido, o Programa Despertando Vocações em conjunto com o Grupo de Estudos e Pesquisas em Administração e Redes de Cooperação (GEPARC), busca por formas mais eficientes com relação a comunicação dentro desses grupos. Assim, filtrando melhor o volume de informações além do compartilhamento de problemas e possíveis soluções criação de um instrumento que possibilite e facilite esse processo de comunicação entre os grupos torna-se necessário, tendo em perspectiva que a facilitação tornaria mais dinâmicas relações sociais. Nesta perspectiva, surge a iniciativa de construir um aplicativo que possa agregarestas informações, que, em perspectivas futuras, podem beneficiar além do Programa PDV, outros programas do IFPE.

Esta pesquisa teve como objetivo criar uma solução criativa através do desenvolvimento deum aplicativo para socialização de problemas e possíveis soluções em grupos de trabalho, tendo como objetivo específicos o Levantamento de demandas de grupos de trabalho, o desenvolvimento de um aplicativo básico para comunicação de grupos e a Ampliar possibilidades para desenvolvimento de melhorias nos aplicativo e como objetivo 
geral o desenvolver um Aplicativo para socialização de problemas e possíveis soluções em grupos de trabalho.

\section{FUNDAMENTAÇÃO TEÓRICA}

A gestão de conflitos tende a crescer de importância dentro das organizações contemporâneas, tendo em vista a importância, cada vez maior, dada às pessoas que nelas trabalham, segundo Chiavenato (1999, p. 323), "constitui o meio interno de uma organização, a atmosfera psicológica, característica em cada organização. O clima organizacional está ligado ao moral e à satisfação das necessidades humanas dos participantes”.

Ainda assim, existem várias variáveis a respeito dos conflitos nas organizações como o número de membros por exemplo, quanto menos pessoas no grupo a tendencia e que a comunicação melhore. Outros fatores pessoais segundo Segundo Megginson, Mosley e Jr (1986, p. 471-472) como: Etnocentrismo, o uso impróprio de práticas gerenciais e percepções diferentes gerar conflitos entre os membros de uma equipe.

Para Bee (2000), a resolução de conflitos passa por uma processo de autocritica, sendo assim desenvolveu 10 ferramentas para realizar-se uma consideração, ou a chamada crítica construtiva: 1) analisar a situação: nesse momento, tem-se o cuidado de identificar qual é o problema, bem como o que necessita ser alterado e por quê; 2) determinar o(s) efeitos(s) e o(s) objetivo(s): visa a determinar o que o indivíduo deve realizar; 3) ajustar-se à receptividade: quem vai realizar a crítica deve identificar se a pessoa a ser criticada está abertapara recebê-la; 4) criar o ambiente propício: visa a propiciar um ambiente no qual quem vai emitir a crítica possa ser entendido e aceito; 5) comunicar-se efetivamente: levar em conta alguns aspectos fundamentais na elaboração de uma crítica, tais como: o que se diz, a maneiracomo se diz, a linguagem corporal; e, ainda, saber ouvir e observar a pessoa criticada além de ajudar o indivíduo criticado a trabalhar com os problemas objeto das críticas; 6) descrever o comportamento que deseja mudar: é fundamental que a pessoa que recebe a orientação tenha em mente o ponto exato do problema; 7) descrever o comportamento desejado: é de suma importância que o indivíduo que recebeu a crítica saiba que necessita apresentar como desempenho ou comportamento; 8) procurar soluções conjuntamente: o indivíduo que critica deve procurar ajudar o criticado, dando-lhe sugestões e/ou ideias; 9) concentrar-se naquilo 
que se acha bom: consiste em alternar mensagens positivas às 4 negativas; e, por fim; chegar a um acordo: este, talvez, seja o item mais difícil, na medida em que ninguém muda seu comportamento ou desempenho sem que concorde.

Atualmente, com a concorrência acirrada que as organizações vivenciam, faz-se necessário criar um diferencial que não seja fácil de ser copiado. Uma das possibilidades é criar um ambiente de trabalho agradável, criativo, competitivo, diferenciado para que seus funcionários possam desenvolver suas atividades, bem como novos produtos, de tal forma que a empresa consiga aumentar sua lucratividade e/ou rentabilidade. Este tipo de ambiente proporciona melhor qualidade de vida, o que acarreta a menor geração de conflitos desnecessários e improdutivos.

Além disso, a internet alterou a forma como as pessoas se relacionam e viabilizou um processo comunicativo capaz de envolver múltiplos agentes reduzindo a distância entre eles. Enquanto meio de comunicação, ela modifica significativamente o tradicionalismo e do unidirecionalíssimo das massas mediáticas ampliando os papéis dos atores sociais, que na lógica da web 2.0, são usuários emissores e receptores da mensagem. Nessa perspectiva, a forma de se relacionar em coletividade ganha outras dimensões, tendo no ciberespaço o ambiente para a reconfiguração das estruturas sociopolítica e cultural.

Para a Targino (1998), Enquanto a informação é um produto, uma substância, uma matéria, a comunicação é um ato, um mecanismo, é o processo de intermediação que permite o intercâmbio de ideias entre os indivíduos. A comunicação é um fenômeno natural e intrínseco ao homem, variando de acordo com as características dos grupos nos quais e entre os quais se efetiva. Como tal, o processo de comunicação pressupõe um estoque comum de elementos preexistentes - linguagem, expressões, códigos etc. -, essencial para facilitar o fluxo informacional.

Para buscarmos entender melhor tal fenômeno e como ele se perpetua para o ambiente digital podemos utilizar como exemplo, os emojis onde figuras ou símbolos podem ser utilizados na comunicação e seu entendimento pode variar de acordo com a cultura, pais e subjetividade do indivíduo ou até mesmo o seu contexto. Tal fato pode ocasionar em ruídos na comunicação os ruídos na comunicação nada mais são do que qualquer elemento que interfira no processo da transmissão de uma mensagem de um emissor para um receptor, onde a linguagem humana é produzida por um conjunto de símbolos que permitem a transmissão de 
ideias e sentimentos. Portanto, como em todo sistema, deve haver sinergia entre os 3 elementos e processos envolvidos, para que ele seja funcional, existindo uma gestão entre os elementos e os processos do sistema, de forma que sua conformação geral dependa das características de cada parte. (SILVA ET AL, 2021)

Alguns autores como Recuero (2012), Primo \& Smaniotto (2006) têm considerado as interações online como conversações por meio do diálogo construído através da linguagem escrita possibilitada pelas tecnologias. Para eles as trocas interativas entre os atores nesses ambientes digitais possuem muitas similaridades com a conversação oral, e ainda que ocorram, na sua maioria, de forma textual, oferece novos rituais e novas formas de negociar um contexto de interação. Para Frigotto et. al. (2005, p.59): “É nesse embate de concepçõesde sociedade e trabalho que se insere a disputa pela educação como prática social mediadora do processo de produção, processo político, ideológico e cultural”.

Sendo assim, o trabalho atual se mostra ímpar na busca da análise e solução para tal desafio que compreende a realidade das relações sociais sendo essas corporativas ou educacionais.

\section{METODOLOGIA}

Com o desenvolvimento da tecnologia de dispositivos móveis que permitem fornecer funções que vão muito além de fazer chamadas ou enviar mensagens, é possível fornecer aos usuários cada vez mais funções e serviços como o acesso aos serviços de instituições financeiras, Uber e Netflix Por exemplo, o desenvolvimento de redes sociais pode ser promovido usando aplicativos executados nos dispositivos.

Por exemplo, o desenvolvimento de redes sociais pode ser promovido usando aplicativos executados nos dispositivos. Graças a este desenvolvimento, os telefones celulares se tornaram Entretenimento, acesso a informações e habilidades de resolução de problemas para integração na vida diária. Numa perspectiva de construir a pesquisa e a aplicação através da construção do aplicativo, foi desenvolvida a metodologia apresentada, na Figura 01: 
Figura 01: Abordagem do trabalho em fases.

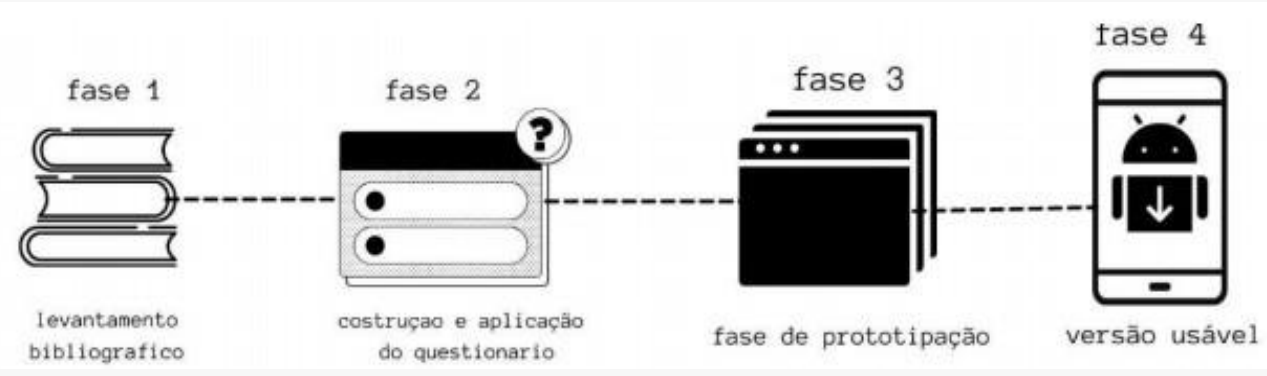

Fonte: Própria (2021).

- Na fase 1, foi realizado um levantamento biblioFigura com os principais autores a respeito do trabalho desenvolvido, levantando assim informações essenciais para a construção do trabalho.

- Já na fase 2, foi realizada uma pesquisa com 10 perguntas com a abordagem qualitativa e quantitativa através de um formulário online, para buscar entender as necessidades e dificuldades dos grupos de trabalho além de entender quem são os sujeitos quecompõe esse grupo.

- Na fase 3, foi realizada uma prototipação do App com funções usáveis e não usáveis e um vídeo curto demostrando com o que o app deve fazer.

- Na última etapa, há um direcionamento para realizar uma versão usável do software tendo em perspectiva o caráter da pesquisa.

\section{RESULTADOS E DISCUSSÃO}

A pesquisa atual foi desenvolvida totalmente de forma remota. Para o desenvolvimento do App se fez necessário um feedback por parte de grupos de pesquisa, para entender quem são esses sujeitos, para buscar conhecer e entender quais eram suas principais dificuldades e desafios. O grupo em questão selecionado foi o GEPARC, onde o formulário virtual foi executado.

Ao total foram realizadas 10 perguntas e obtivemos 16 respostas, a primeira pergunta do questionário diz a respeito do sexo biológico dos indivíduos como podemos observar na Figura 02, abaixo, temos um equilíbrio em relação ao número de participantes masculinos e femininos.

Figura 02: Sexo. 
1. Qual seu sexo?

16 respostas

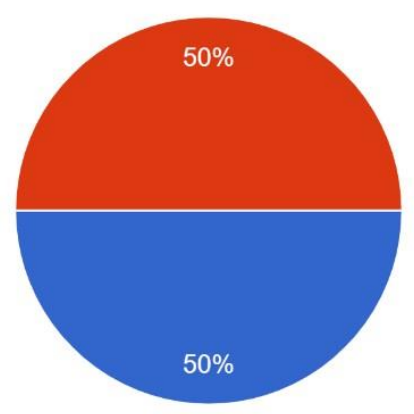

1.masculino

2.feminino

Fonte: Própria (2020).

Logo após, buscando entender melhor quem são esses sujeitos foram realizadas outras duas perguntas “Qual seu nível de Escolaridade?” e "A qual desses grupos você pertence?” como podemos ver nas Figuras 03 e 04, respectivamente, abaixo. O número de indivíduos reforça o pilar fundado do Grupo de pesquisa estudado, onde obtivemos cerca de $50 \%$ dos entrevistados se identificando enquanto alunos, caráter esse associado ao protagonismo estudantil e desenvolvimento estudantil. Além disso, o número de graduação em andamento e nível técnico em andamento são somados $50,1 \%$.

Figura 03: Nível de Escolaridade.

\section{Qual seu nivel de Escolaridade?}

16 respostas

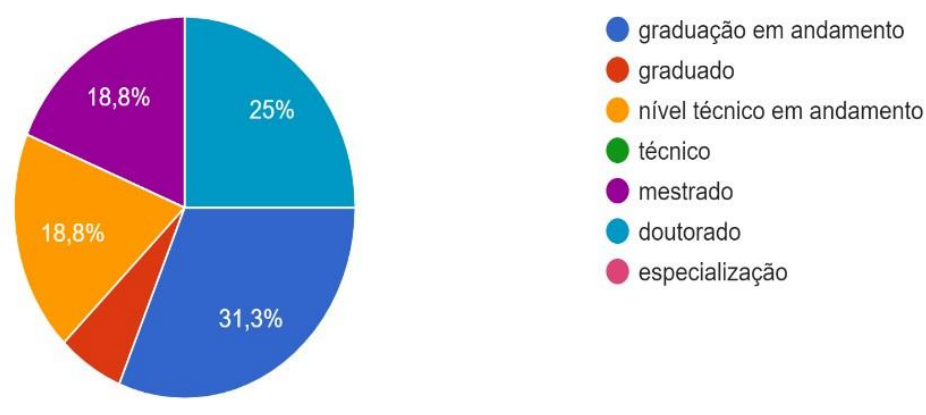

Fonte: Própria (2020).

Figura 04: A qual dos grupos o individuo pertence. 


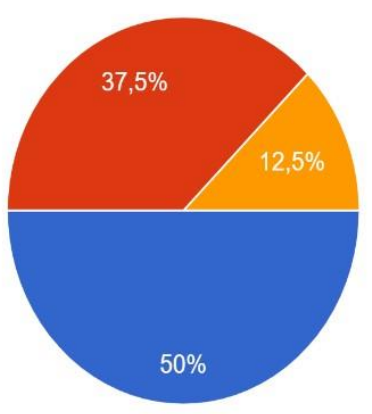

Fonte: Própria (2020).

Também foi questionado aos participantes, como eles avaliavam a comunicação noseu grupo de trabalho, podemos notar, como de acordo ao Figura 05, que a maioria julgou a comunicação como sendo regular com cerca de 43,8\%. Tal fato, pode ser devido a cultura digital dentro do grupo já se fazer presente, com uso de ferramentais como WhatsApp, google Meet e Zoom.

Figura 05: Nível de Escolaridade.

6. avalie a comunicação no seu grupo de trabalho do PDV:

16 respostas

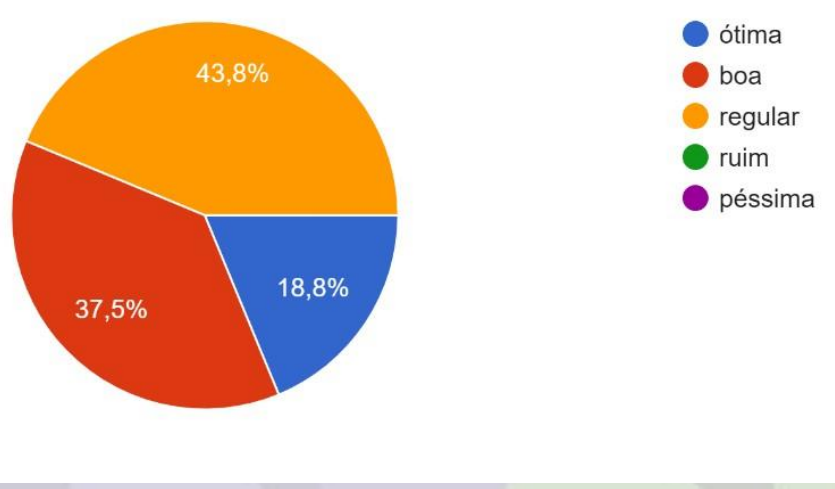

Fonte: Própria (2020).

A fim de melhorar, a comunicação foi questionada aos participantes na pergunta 7 "Tratando-se da Comunicação, que fator você acredita que poderia melhorar a comunicação no seu grupo de trabalho?". Algumas das respostas mais pontuais foram regularidade, 
Feedback mais rápido por parte dos membros, Implantar novas ferramentas de comunicação, Mais disponibilidade da equipe e um meio mais organizado do que mensagens no WhatsApp, Tempo de resposta às demandas; porcentagem de participação na alimentação do fluxo de informações e Organização das principais pautas que precisam ser resolvidas, não necessariamente de forma síncrona já que todos podem ter horários disponíveis diferentes e reduzidos. Determinar um prazo de horas ou dias para poder opinar sobre essas pautas.

Além disso, a pergunta 8 foi "Qual o principal desafio você encontra na comunicação do em seu grupo de trabalho?" algumas das principais trespostas foram, "horários disponíveis de cada participante", "Tempo de conciliar encontros síncronos", "Quando nos comunicamos pelo Whatsapp, me perco devido ao número excedente de mensagens", "O afastamento social acaba deixando o horário livre dos membros completamente confuso, creio que não haja algo específico para ser feito no momento. Tentando imaginar um cenário onde tudo ocorra presencialmente, todos terão um horário relativamente padronizado facilitando tudonovamente, o que acho que já seria o suficiente para uma comunicação fluida.”

Podemos notar alguns padrões nas respostas, primeiramente a maioria fala do tempo, horário, organização, comunicação e o afastamento social devido a pandemia de corona vírus iniciado no ano de 2020 no Brasil. Que afetou principalmente os eventos e encontros que normalmente eram de forma presencial, nem todas as atividades podem ser realizadas de forma remota ainda, no brasil uma das principais barreiras para a educação foi dar acesso a infraestrutura para os alunos como internet e equipamentos eletrônicos. Segundo o IBGE (2020), 64,8\% dos alunos de escolas públicas tinham o aparelho para uso pessoal e nem todos eles tinham acesso à rede.

Na pergunta de número 9 foi realizado o seguinte questionamento ". Quais as principais demandas de TI que você gostaria de otimizar no seu Grupo de Trabalho?", algumas das respostas foram, "Um aplicativo para celular que desse mais opções que o a rede social. Que pudéssemos agendar conjuntamente reuniões. por exemplo.”, “A atualização constante as atividades e pendências do grupo.”, “1. App de acompanhamento de frequência dos pdvlianos que os estudantes alimentem a $\mathrm{CH}$ no PDV, a escola campo ter como atestar que o estudante estava lá (ou uso do GPS do smartphone p atestar que o aluno se encontra em atividade externa no local informado no plano de trabalho semanal). 2. App de compartilhamento foto/vídeo/descrição, onde os alunos compartilhassem as experiências em 
tempo real e os administradores já tivessem como compartilhar nas redes sociais do curso (Biólogos nas redes) 3. App simplificado de acompanhamento de execução de planos de trabalho de cada GT. 4. O nosso pessoal do GT de trilhas guiadas poderia ter uma ferramenta p "digitalizar "as trilhas ou os pontos de interatividade (estilo Google street view) para que as pessoas possam online "andar" pelas unidades de conservação da natureza sem sair de casa. Assim estimula a curiosidade para uma visita presencial e serve se ferramenta de educação ambiental."

$\mathrm{Na}$ última questão a de número 10 , foi perguntado "Você poderia sugerir alguma inovação para incrementar o trabalho no GT? Qual?” algumas das respostas mais interessantes obtidas foram, "Criação de um canal mais organizado para comunicação." "Uma plataforma ou aplicativo para gestão de projetos e definição de responsabilidades ou afazeres voltada a equipes de Pesquisa e desenvolvimento tecnológico".

Visto o resultado da pesquisa e as necessidades do grupo, se iniciou o processo desenvolvimento de uma primeira versão de App chamado de RemenberMe, que possui como proposito lembrar a os participantes de determinado grupo uma reunião ou atividade. 06.

Na primeira tela do aplicativo podemos ver uma tela clássica de login como na Figura 
Figura 06: Tela de Login do APP.

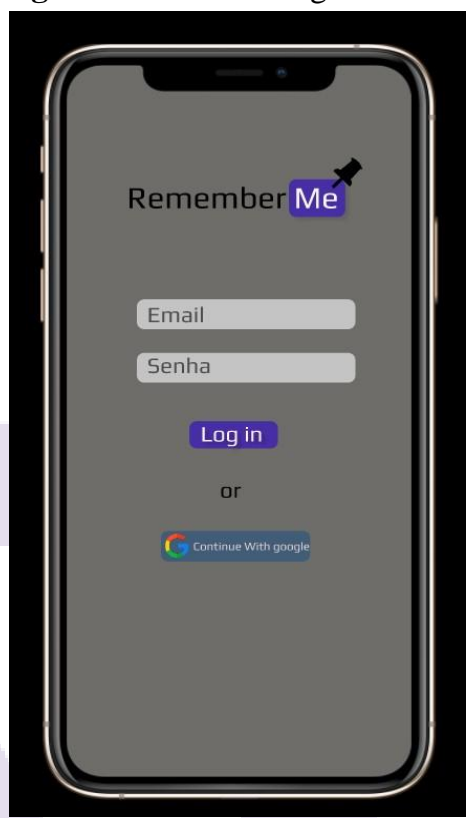

Fonte: Própria (2021).

O login pode ser realizado de forma mais rápida vinculando ao google, abaixo se encontra a tela do menu, onde temos algumas as principais funções do aplicativo (Figura 07).



Fonte: Própria (2021).

A Função Meus lembretes, segue conforme o fluxo da imagem abaixo (Figura 08). 
Figura 08: Função Lembrete.

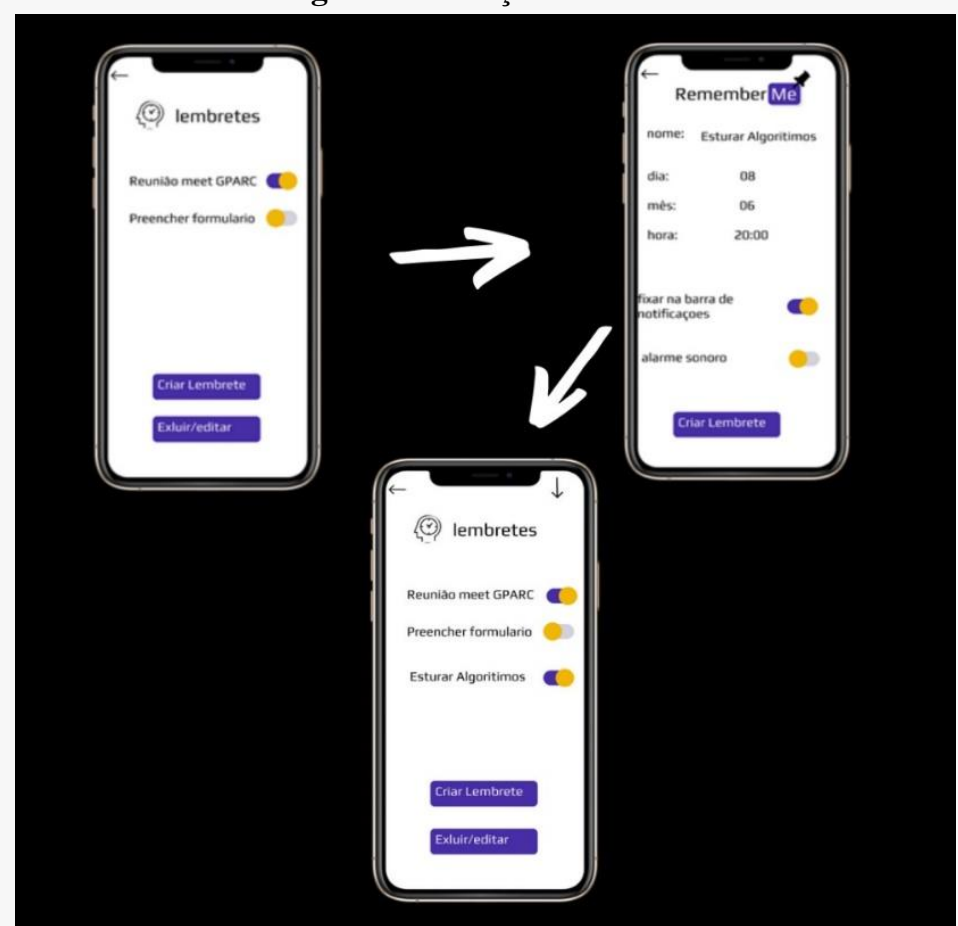

Fonte: Própria (2021).

Após realizar as configurações do lembrete ele irá ficar fixado na barra de notificações, em formato de lembrete informando a quantidade de tempo que falta para o evento (Figura 09).

Figura 09: Função Lembrete fixada em Notificações

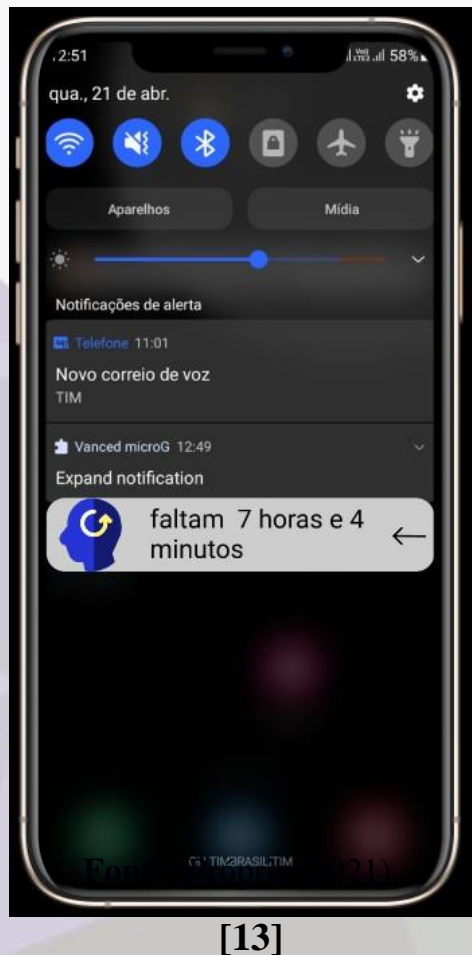


O APP também possui a função "Criar Grupo", que facilita a cada coordenador gerenciar suas atividades e gerenciar o seu sub-grupo de trabalho (Figura 10).

Figura 10: Função Lembrete fixada em Notificações

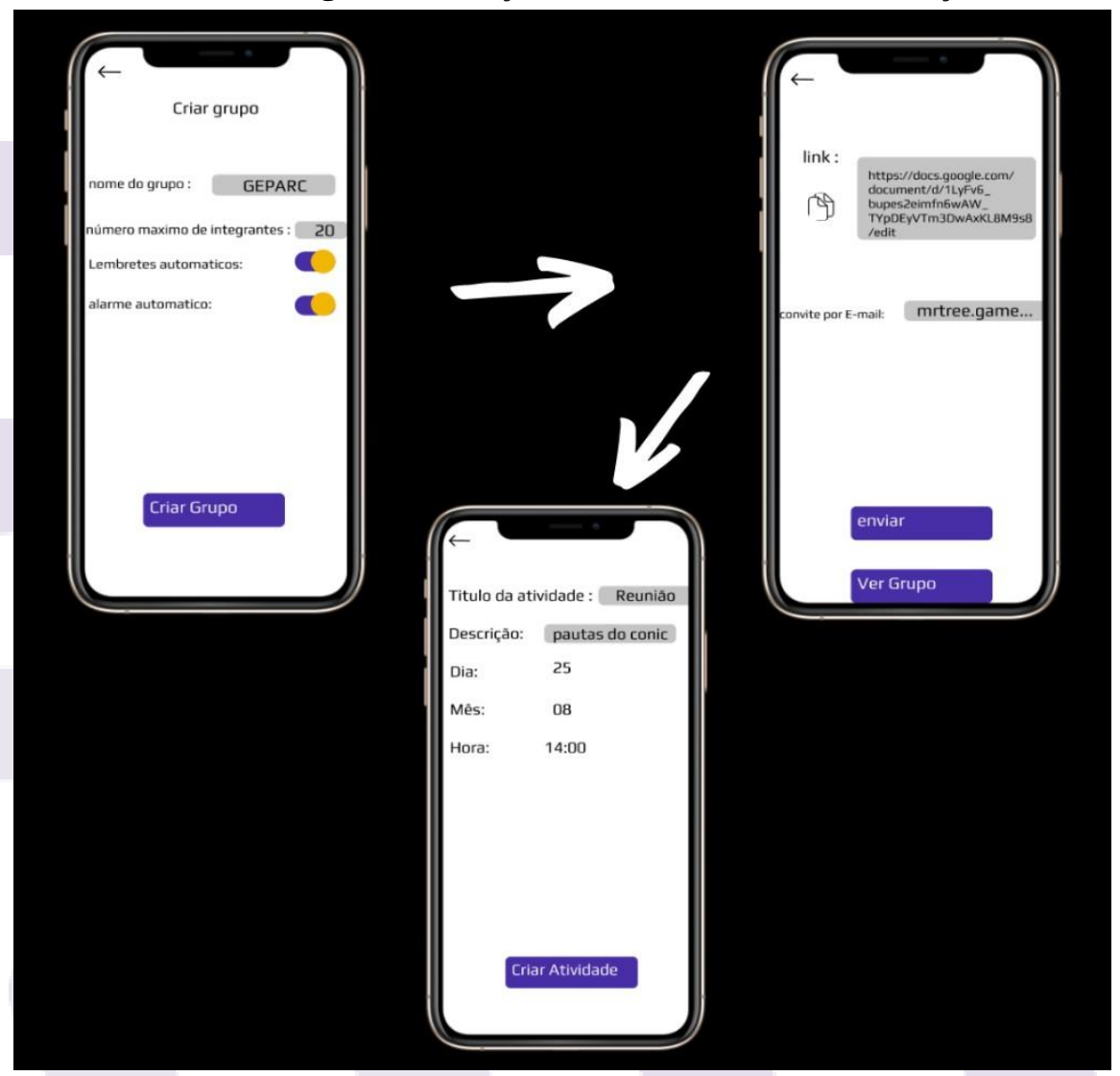

Fonte: Própria (2021).

O App possui funções específicas para gerenciamento da comunicação com o Grupo de Trabalho, como "Enviar convite" (Figura 11) e "Visualizar Tarefas" (Figura 12). 


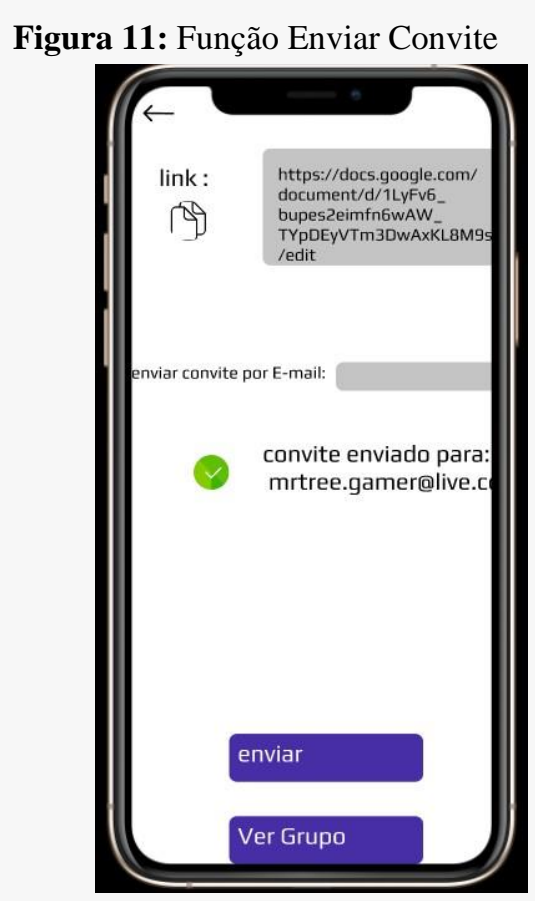

Fonte: Própria (2021).
Figura 12: Função Visualizar Tarefas

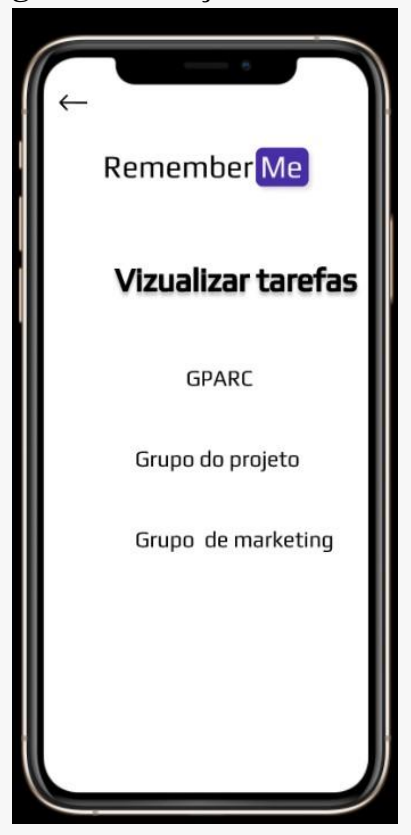

Fonte: Própria (2021).

Por último, foi implementada função de Lembrete, que consiste em inserir lembretes de Atividades que podem ser excluídos pelo gestor do grupo, ou afixados, conforme necessidade, como pode ser visto na Figura 13.

Figura 13: Função Lembrete com exclusão e fixação de atividades.

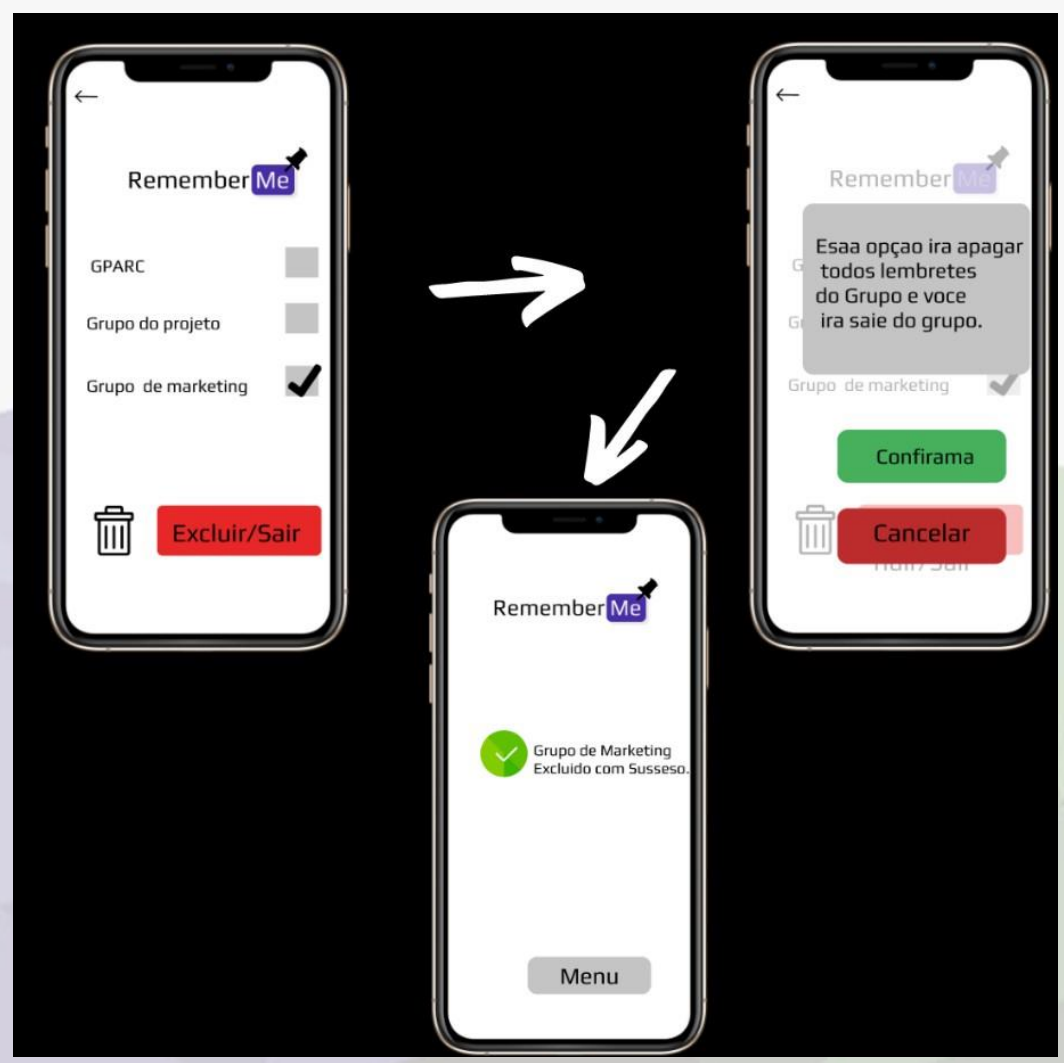

Fonte: Própria (2021). 
Desta forma, com base no que foi pesquisado, o aplicativo conseguirá incrementar melhorias no processo de Gestão dos Grupos de Trabalho, principalmente na perspectiva de gerenciamento da comunicação, com informações direcionadas.

\section{CONCLUSÕES}

Como principal resultado da pesquisa se apresenta o Software de gestão de grupos, desenvolvido com base em aplicação de questionário para levantamento de demandas "in loco" do Grupo de Pesquisa GEPARC. São bastantes promissoras as aplicações desse aplicativo, que pode ser implementa não só no meio educacional mais também em ambientes corporativos onde a necessidade do gerenciamento de tempo se faz mister, já que a comunicação e o gerenciamento de tempo são desafios da modernidade.

Como primeiro passo buscando ser a pesquisa pioneira nesse sentido, ainda há bastante espaço para o desenvolvimento do sistema abordado durante o trabalho atual, para prosseguir o seu desenvolvimento e possivelmente transformar esse produto/serviço em uma futura Startup ou até mesmo vender a ideia para empresas ou parceiros comerciais quepossam financiar os custos do seu desenvolvimento e da operação.

Diante do exposto, foi um desafio criativo e técnico o desenvolvimento desse projeto, as possibilidades para se continuar devem ser bastante estudadas, debatidas e continuadas caso seja viável. 


\section{REFERÊNCIAS}

BARROS, ALERRANDRE. Agencia de noticias IBGE. 2021. Disponível em: <https://agenciadenoticias.ibge.gov.br/agencia-noticias/2012-agencia-de-noticias/noticias/305 22-internet-chega-a-88-1-dos-estudantes-mas-4-1-milhoes-da-rede-publica-nao-tinham-acesso -em-2019\#: :text=PNAD\%20Cont\%C3\%ADnua-,Internet\%20chega\%20a\%2088\%2C1\%25 $\% 20$ dos\%20estudantes\%2C\%20mas\%204,n\%C3\%A3o\%20tinham\%20acesso\%20em\%20201 9>. Acesso em: 11 jun. 2021.

BEE, Roland. Feedback. São Paulo: Nobel, 2000.

CHIAVENATO, Idalberto. Introdução à Teoria Geral da Administração. 1999.BRASIL. Lei de Diretrizes e Bases da Educação Nacional, LDB. 9394/1996

Basalla, G. São Paulo: Makron Bools, 1999. (1988). The evolution of technology. Cambridge: Cambridge University Press.

DA SILVA, Marcelo Moro; SANTOS, Marilde Terezinha Prado. Os paradigmas de desenvolvimento de aplicativos para aparelhos celulares. Revista TIS, v. 3, n. 2, 2014.

FRIGOTTO, Gaudêncio. Concepções e mudanças no mundo do trabalho e ensino médio. In: FRIGOTTO, Gaudêncio.

CIAVATTA, Maria. RAMOS, Marise. (Orgs).Ensino Médio Integrado: concepção e contradições. São Paulo: Cortez, 2005.

TARGINO, MARIA DAS GRAÇAS, M.G.T COMUNICAÇÃO CIENTÍFICA: uma revisão de seus elementos básicos. 1998.

Tese de doutorado (ESPECIALIZAÇÃO EM ...) -Universidade de Brasília, Brasilia.

MEGGINSON, Leon C. \& MOSLEY, Donald C \& Jr, Paul H. Pietri. Administração: conceitos e Aplicações. São Paulo: Harbra , 1986.

Oliveira,C.C., Menezes, E.I., Moreira, M. (2001) Ambientes Informativos de Aprendizagem: produção de software educativo. Campinas: Editora Papitus.

PRIMO, A. (Org.). Interações em rede. Porto Alegre: Sulina, 2013.

5 PRIMO, A. Avaliação qualitativa de interações em redes sociais: relacionamentos no blog Martelado. SãoPaulo. Comunicação, Mídia e Consumo, v.4, p.137-158, 2007. PRIMO, A.; SMANIOTTO, A.R. Blogs como espaço de conversação: interações conversacionais na comunidade de blogs insanus. 
RECUERO, Raquel. E-compos, v.1, n.5, 2006. RECUERO, R. A conversação em rede: comunicação mediada por computador e redes sociais na Internet. Porto Alegre: Sulina, 2012.

RECUERO, Raquel. Redes Sociais na Internet. Porto Alegre: Sulina, 2009.

Redes Sociais na Internet. Porto Alegre: Sulina, 2. ed., 2011 SEBRAE.

Conheça o Programa Nacional de Educação Empreendedora. [S.1], [2019?].

Disponível em:https://cer.sebrae.com.br/programa-nacional-de-educacaoempreendedora/. Acesso em: 10 set.2020.

SILVA, Leandro. GESTÃo de Pessoas na Perspectiva do Ambiente de Trabalho Multigeracional. [S. 1.], 17 abr. 2019. Disponível em:

https://administradores.com.br/artigos/gestao-de-pessoas-naperspectiva-do-ambiente-de-trabal homultigeracional. Acesso em: 24 mar. 2021.

SILVA, CIBELE EVELYN DE MELO; RITA DE CASSIA GOMES, R.C.G; MARIA HELENA VELOSO SALGADO, M.H.V.S. GESTÃO DE CONFLITOS: COMO ATENUAR RUÍDOS NA COMUNICAÇÃO CORPORATIVA. Congresso Nacional de

Iniciação Cientifica, ano $18^{\circ}$, p. 1-4, DATA. Disponível em: <http://conic-semesp.org.br/anais/files/2018/trabalho-1000001728.pdf>. Acesso em: 8 jul. 2021. 